\title{
Crioconservação de sementes de mamona das variedades nordestina e pernambucana ${ }^{1}$
}

Francisco de A. C. Almeida ${ }^{2}$, Ailton M. de Morais $^{3}$, Julita M. F. C. Carvalho ${ }^{4}$ \& Josivanda P.G. de Gouveia ${ }^{2}$

\footnotetext{
1 Parte da dissertação de Mestrado do segundo autor, curso de pós-graduação em Engenharia Agrícola,bolsista CAPES convênio UFPB/Embrapa Algodão

2 DEAg/CCT/UFCG. CEP 58109-970, Campina Grande, PB. E-mail: diassis@deag.ufpb.br (Foto)

${ }^{3}$ Biólogo, M.Sc. Trav. Epitácio Pessoa, 472, CEP 58680-000, Taperoá, PB

4 Embrapa Algodão. CP 174, CEP 58107-720, Campina Grande, PB
}

Protocolo $166-26 / 11 / 2001$

\begin{abstract}
Resumo: É grande a importância da mamoneira (Ricinus communis L.) para a economia do semiárido nordestino, que é responsável por $80 \%$ da produção nacional, no entanto durante 1970 e 2000, a produção líquida dessa oleaginosa foi reduzida na mesma percentagem. Registrou-se também a existência de aproximadamente 90 tipos diferentes de sementes empregadas no cultivo desta Euforbiaceae. Devido a este problema, o trabalho desenvolvido no Laboratório de Processamento e Armazenamento de Produtos Agrícolas do DEAg/UFPB, objetivou desenvolver técnicas de crioconservação para duas variedades de Ricinus communis, com vistas a uma armazenagem segura e por tempo indefinido. $O$ delineamento experimental utilizado foi o inteiramente casualizado, com os dados obtidos nos $7^{\circ}$ e $14^{\circ}$ dias depois da semeadura, dispostos em um arranjo fatorial $2 \times 3 \times 2 \times 2$ (duas variedades, três períodos de crioconservação, duas temperaturas de crioconservação e dois tipos de acondicionamento) com oito repetições de vinte e cinco sementes cada uma. Os dados obtidos foram submetidos à análise de variância e as médias dos fatores qualitativos comparadas pelo teste de Tukey, a $5 \%$ de probabilidade. Com os resultados obtidos concluiu-se que: o nível máximo de umidade para a crioconservação das sementes das duas variedades de Ricinus communis (nordestina e pernambucana) encontra-se entre 4 e $10 \%$ base úmida; os melhores resultados de qualidade fisiológica foram obtidos aos 30 dias da crioconservação, podendo essas sementes serem crioconservadas tanto no vapor $\left(-176^{\circ} \mathrm{C}\right)$ como na imersão $(-196$ ${ }^{\circ} \mathrm{C}$ ) em nitrogênio líquido; o canister de alumínio utilizado para acondicionar as sementes mostrouse superior ao de PVC.
\end{abstract}

Palavras-chave: nível máximo de umidade, Ricinus commumis L., nitrogênio líquido

\section{Cryoconservation of nordestina and pernambucana varieties of castor bean seeds}

\begin{abstract}
The castor bean (Ricinus communis L.) has great importance for the economy of the semi-arid region of the northeast of Brazil, responsible for $80 \%$ of the national production, but during 1970 and 2000, the net production of this oil crop was reduced. Existence of some 90 different types of seeds used in the cultivation of this Euforbiaceae was also verified. Due to this problem, the Processing and Storage of Agricultural Products Laboratory of DEAg/UFCG, has tried to develop cryoconservation technique for two varieties of Ricinus communis, in order to obtain a secured storage for an indefinite time. The experimental delineation was a completely randomized, with the data obtained on the $7^{\text {th }}$ and $14^{\text {th }}$ day after sowing, in a factorial scheme $2 \times 3 \times 2 \times 2$ ( 2 varieties $\times 3$ cryoconservation periods $\times 2$ cryoconservation temperatures $\times 2$ types of conditioning) with eight repetitions of twenty-five seeds each. The data obtained were submitted to an variance analysis and the means were compared by the Tukey's, test at $5 \%$ of probability. From the results obtained it can be concluded that: the maximum level of humidity for the cryoconservation of the seeds of the two varieties of Ricinus communis (nordestina and pernambucana) is between 4 and $10 \%$ on wet basis; the best results of physiological quality were obtained after 30 days of cryoconservation and may either be cryoconserved in the vapor $\left(-176^{\circ} \mathrm{C}\right)$ or by immersion $\left(-196^{\circ} \mathrm{C}\right)$ in liquid nitrogen; for storage of seeds, canister of aluminum proved to be better than that of PVC.
\end{abstract}

Key words: maximum level of humidity, Ricinus commumis L., liquid nitrogen 


\section{INTRODUÇÃO}

A cultura da mamona tem grande importância para a economia do semi-árido nordestino, por sua resistência à seca, como fator fixador de mão-de-obra, gerador de emprego e de matéria-prima indispensáveis ao desenvolvimento da região e do País (Azevedo et al., 1997). Segundo o Levantamento Sistemático da Produção Agrícola (IBGE, 1975 e 2001) o Brasil figurou, por décadas, como o maior produtor mundial e maior exportador de seu principal subproduto, o óleo.

A técnica da crioconservação, isto é, o armazenamento em nitrogênio líquido $\left(-196{ }^{\circ} \mathrm{C}\right)$ proporciona o potencial para uma preservação sem limites de tempo, com a redução do metabolismo a níveis tão baixos que todos os processos bioquímicos são significativamente reduzidos e a deterioração biológica é virtualmente paralisada (Kartha, 1985). Os outros métodos de conservação somente adiam a deterioração por um período de tempo determinado e específico, de acordo com o material e a espécie em questão.

Outras vantagens da crioconservação estão relacionadas com: 1) o pequeno espaço a ser ocupado por um banco de germoplasma mantido em nitrogênio líquido; 2) a simplicidade de manuseio das condições, bastando manter-se o nível de nitrogênio líquido nos botijões, reabastecendo-o a cada 40-60 dias e 3) o baixo custo do armazenamento, uma vez que não exige sistema de refrigeração nem de eletricidade.

Henshaw et al. (1980) alertam que, embora seja possível crioarmazenar várias partes da planta, os sistemas organizados, como sementes e embriões, são os mais adequados para a conservação de recursos genéticos.

Cunha (1996) descreve que o teor de umidade da semente é, provavelmente, o mais crítico fator para o sucesso da crioconservação e se a umidade da semente é muito alta, observa-se a sua morte instantânea durante o processo de congelamento e/ou descongelamento.

Existe um nível máximo de umidade para o congelamento (High Moisture Freezing Limit-NMU) acima do qual a viabilidade da semente é reduzida durante o mesmo (Stanwood, 1985). Este limite crítico é, em geral, uma faixa relativamente estreita de umidade dentro da espécie, mas pode variar entre espécies.

González-Benito et al. (1998) estudaram a viabilidade de sementes crioarmazenadas de algodão Gossypium hirsutum L. (CNPA 4M, CNPA 5M, CNPA Precoce 1, CNPA precoce 2 e Coker 312) como um método de conservação do patrimônio genético, na qual as sementes foram submetidas a dessecação e/ou imersão, em nitrogênio líquido. A germinação não foi afetada por nenhum dos tratamentos nas cultivares CNPA 4M, CNPA Precoce 1 e Coker 312 e a viabilidade das sementes das cultivares CNPA 5M e CNPA Precoce 2 foi reduzida quando estas sementes foram dessecadas e o teor de umidade baixou de 9,8 e $15,6 \%$ para 2,8 e $3 \%$, respectivamente; entretanto, a germinação das sementes dessecadas foi aumentada depois da imersão em nitrogênio líquido.

Almeida et al. (2000) estudaram o efeito da crioconservação sobre 10 espécies de leguminosas de interesse econômico para a Espanha e Brasil, tendo concluído que antes de se generalizar o uso da crioconservação em sementes de leguminosas, deve-se avaliar, nas diferentes espécies e cultivares, o efeito de possíveis alterações anatômicas sobre a viabilidade e o vigor das sementes e, ainda, que a crioconservação se apresenta como uma boa alternativa para a conservação das sementes de Lathyrus cicera, L. sativus, Lens culinaris, Lupinus albus, Phaseolus vulgaris, Pisum sativum, Vica articulata, V.faba, V. monanthos e V. sativa.

Iriondo et al. (1992) analisaram a influência da conservação em nitrogênio líquido em diversas espécies de plantas silvestres, com teores de umidade e tempo de exposições diferentes. Os resultados não indicaram diferenças significativas na maioria das espécies em relação ao percentual de germinação, seja nas amostras de sementes com teores de umidade diferente, seja nas amostras de sementes com diferentes tempos de exposição ao nitrogênio líquido.

Stanwood (1985) estudando taxas de congelamento e descongelamento para sementes de alface (Lactuca sativa L.) e gergelim (Sesamum indicum L.) constatou, para a primeira espécie, que a $19 \%$ de umidade suas sementes mantiveram a viabilidade apenas quando submetidas a uma taxa de congelamento de $200{ }^{\circ} \mathrm{C} \mathrm{min}^{-1}$ (alta taxa) enquanto as sementes de gergelim germinaram $100 \%$, independentemente do grau de umidade, quando a taxa de congelamento foi baixa, tendo reduzido a sua viabilidade junto com o seu grau de umidade na crioconservação, sob alta velocidade de congelamento.

Apesar da crioconservação ter sido testada em diversas espécies, ainda não existe uma rotina de laboratório que possa garantir a conservação do germoplasma vegetal. A complexidade, tanto técnica como biológica, exige serem observados, com atenção, para o sucesso da crioconservação, o grau de umidade da semente, a velocidade de congelamento e descongelamento e danos físicos à semente (Stanwood \& Bass, 1981; Vertucci, 1989; Engelmann, 2000; Almeida, 2000).

Por tudo que foi exposto, o trabalho teve como objetivo estudar um protocolo de crioconservação para duas variedades de mamona (Ricinus communis L.) recomendadas para o Nordeste do Brasil, a fim de se assegurar sua conservação ex situ para usos futuros, através de banco de germoplasma e mediante a determinação do nível máximo de umidade (NMU) e da avaliação da qualidade fisiológica das sementes submetidas ao vapor $\left(-176{ }^{\circ} \mathrm{C}\right)$ e a imersão do nitrogênio líquido, acondicionadas em canister de PVC e de alumínio, por períodos de 3,30 e $60 \mathrm{~d}$.

\section{MATERIAL E MÉTODOS}

Para o estudo da influência das condições de armazenamento das sementes de duas variedades (pernambucana e nordestina) de mamona, Ricinus communis, sobre a sua viabilidade (germinação e vigor) estudou-se, previamente, o nível máximo de umidade (NMU) que as sementes de cada variedade poderiam suportar, ao serem imersas em nitrogênio líquido.

A obtenção da umidade inicial das duas variedades de Ricinus communis foi determinada por meio do método gravimétrico, com a utilização de estufa a $105^{\circ} \mathrm{C}$, que se baseia no processo da água extraída das sementes durante a sua permanência na estufa por $24 \mathrm{~h}$, calculando-se os resultados mediante a Eq. (1):

$$
\% \mathrm{U}=\frac{\mathrm{Pi}-\mathrm{Pf}}{\mathrm{Pi}-\mathrm{t}} \times 100
$$


em que:

U - grau de umidade em percentagem de base úmida (b.u), \%

Pi - peso inicial da subamostra, $g$

Pf - peso final da subamostra, $g$

$\mathrm{t} \quad$ - tara do recipiente, $\mathrm{g}$

Para a caracterização do material quanto ao teor da umidade, os lotes das duas variedades de Ricinus Communis eram submetidos aos processos de hidratação ou secagem, até alcançarem os teores de umidade estabelecidos para a instalação dos diferentes ensaios de determinação do NMU $(4 ; 6 ; 8 ; 10$ e $12 \%$, b.u). A perda ou ganho de água pelas sementes, foi determinado por meio da fórmula recomendada por Almeida et al.(1997).

$$
\operatorname{Pf}=\mathrm{Pi} \times \frac{100-\mathrm{Ui}}{100-\mathrm{Uf}}
$$

em que:

$$
\begin{array}{ll}
\mathrm{Pf} & \text { - peso final da amostra, } \mathrm{g} \\
\mathrm{Pi} & \text { - peso inicial da amostra, } \mathrm{g} \\
\mathrm{Ui} & \text { - umidade inicial das sementes (b.u), } \% \\
\mathrm{Uf} & \text { - umidade desejada das sementes (b.u), } \%
\end{array}
$$

Em seguida, foi avaliada a qualidade fisiológica das sementes, mediante o Teste Padrão da Germinação (TPG) conforme procedimentos contidos em Brasil (1992) exceto o número de sementes, que foi de $200 \mathrm{em} 8$ repetições de 25 sementes, tendo como substrato o rolo de papel do tipo Germitest, umedecido com água destilada. Depois de confeccionados os rolos, estes foram depositados uniformemente em posição vertical dentro do germinador, com alternância de temperatura $\left(20-30^{\circ} \mathrm{C}\right)$ automática e umidade relativa do ar entre 90 e $95 \%$.

Consideraram-se germinadas as sementes que emitiram ao menos $30 \mathrm{~mm}$ de radícula nos $7^{\circ} \mathrm{e} 14^{\circ}$ dias depois da semeadura. Ademais, da primeira contagem do TPG, levou-se a cabo um ensaio para a determinação do peso seco das plântulas consideradas normais no $14^{\circ}$ dia da semeadura, obedecendo aos mesmos procedimentos descritos para o TPG.

Para o umedecimento das sementes, três subamostras de $200 \mathrm{~g}$ de cada variedades de Ricinus communis, foram distribuídas entre seis folhas de papel-toalha medindo, cada uma, $100 \times 22 \mathrm{~cm}$; em seguida, estas foram umedecidas com água destilada dentro de uma bandeja plástica, até a saturação, deixando-se escorrer o excesso de umidade.

Posteriormente, formaram-se rolos os quais foram colocados em uma câmara, a uma temperatura constante de $20 \pm 3{ }^{\circ} \mathrm{C}$ e umidade relativa de $95 \pm 2 \%$, onde permaneceram até alcançar as umidades de 8,10 e $12 \%$ b.u.

Para a secagem das sementes, duas subamostras de $200 \mathrm{~g}$ de cada uma das variedades de Ricinus communis, foram colocadas em estufa com circulação de ar e temperatura constante de $33 \pm 2{ }^{\circ} \mathrm{C}$, até atingirem as umidades desejadas ( $4 \mathrm{e}$ $6 \%$ b.u.).

Formados os lotes ( $200 \mathrm{~g}$ cada um), das duas variedades de Ricinus communis com os teores de umidade de 4, 6, 8, 10 e 12\% b.u. estabelecidas para os ensaios, estes eram acondicionados em tubos cilíndricos de alumínio (canister) os quais, com as sementes, eram resfriados em câmara a $-30^{\circ} \mathrm{C},-176^{\circ} \mathrm{C}$, por um período de $3 \mathrm{~h}$ para cada temperatura, sendo depois, essas sementes, imersas em nitrogênio líquido $\left(-196^{\circ} \mathrm{C}\right)$ onde permaneceram por $3 \mathrm{~d}$.

Decorridos os $3 \mathrm{~d}$ de crioarmazenamento, retiravam-se os canister dos botijões criogênicos e se submetia as sementes a um descongelamento gradativo $\left(-196 ;-170 ;-30\right.$ e $\left.\pm 25^{\circ} \mathrm{C}\right)$ com intervalo de $3 \mathrm{~h}$ para cada temperatura; em seguida, foram feitos os testes de qualidade fisiológica das sementes (germinação e vigor) obedecendo-se aos procedimentos já descritos.

Determinado o NMU, separou-se um lote de 2.500 sementes das duas variedades de Ricinus communis e se ajustou seu teor de umidade para $6 \%$ b. u.; logo após, as sementes foram acondicionadas em tubos cilíndricos de PVC e de alumínio, para posterior congelamento, sendo que um lote de sementes foi imerso no nitrogênio líquido $\left(-196^{\circ} \mathrm{C}\right)$ e o outro no vapor do nitrogênio $\left(-176^{\circ} \mathrm{C}\right)$ durante 3,30 e 60 dias; depois deste período, as sementes foram submetidas ao descongelamento e avaliada a sua qualidade fisiológica, mediante teste de germinação e vigor.

O delineamento estatístico utilizado foi o inteiramente casualizado em um arranjo fatorial $2 \times 3 \times 2 \times 2$ ( 2 variedades x 3 períodos de crioconservação x 2 temperaturas de crioconservação x 2 tipos de acondicionamento) com oito repetições de vinte e cinco sementes cada uma. Os dados obtidos foram submetidos à análise de variância, pelo programa computacional ASSISTAT, versão 6.2 (Silva, 1996) e as médias dos fatores qualitativos comparadas pelo teste de Tukey, a 5\% de probabilidade.

\section{RESULTADOS E DISCUSSÃO}

\section{Nível máximo de umidade para a crioconservação (NMU)}

Pela análise de variância, observou-se diferença estatística para o vigor das sementes de mamona expresso em grama de matéria seca, das variáveis variedades e umidade e para a interação dessas variáveis. (Tabela 1 ). $\mathrm{O}$ resultado não significativo da interação variedade versus umidade para a germinação e sua primeira contagem, indica que as variáveis atuam isoladamente, isto é, o comportamento de uma não interfere no desempenho da outra.

Tabela 1. Análise de variância da viabilidade das sementes de duas variedades de Ricinus communis, após a crioconservação em nitrogênio líquido a $-196^{\circ} \mathrm{C}$, durante três dias

\begin{tabular}{lcrrr}
\multicolumn{1}{c}{$\begin{array}{c}\text { Fonte de } \\
\text { Variação }\end{array}$} & $\begin{array}{c}\text { Grau de } \\
\text { Liberdade }\end{array}$ & Germinação & \multicolumn{2}{c}{ Vigor } \\
\cline { 4 - 6 } & & & $1^{\text {a }}$ Contagem & Mat. Seca \\
\hline Variedade (V) & 1 & $33,33 * *$ & $33,33 * *$ & $576,07 * *$ \\
Umidade (U) & 5 & $1138,13 * *$ & $1138,13 * *$ & $406,55 * *$ \\
V x U & 5 & $0,53 \mathrm{~ns}$ & $0,53 \mathrm{~ns}$ & $10,13 * *$ \\
Resíduo & 36 & & & \\
Total & 47 & & & \\
** Significativo a 1 \% de probabilidade \\
ns Não significativo
\end{tabular}


A viabilidade das variedades nordestina e pernambucana de Ricinus communis foi depois da crioconservação por três dias em nitrogênio líquido de 71,33 e 68,00\% respectivamente, com diferença estatística entre elas (Tabelas 2 e 3); no entanto, quando se compara o valor absoluto individual dessas médias, constata-se que não há diferença marcante entre elas, concluindo-se, que a diferença se deve, provavelmente, ao patrimônio genético de cada variedade, não tendo havido, em valores absolutos, efeito da crioconservação sobre a viabilidade das variedades estudadas. Este comportamento foi observado em Sesamum indicum por Batista (2000) depois de submeter três variedades de sementes desta oleaginosa a crioconservação, por um período de cinco dias.

Ainda nas Tabelas 2 e 3 constata-se, para os níveis de umidade em que as sementes foram crioarmazenadas por três dias, com o objetivo de se conhecer o nível máximo de umidade acima do qual a semente perde sua viabilidade (NMU) que este se encontra na faixa de 4 a $10 \%$ b.u., visto que neste intervalo as médias dos fatores utilizados para se determinar o NMU, não diferiram do ponto de vista da estatística porém, por se tratar de uma espécie rica em óleo, os menores teores de umidade (4 a 8\%

Tabela 2. Valores médios da viabilidade das sementes de duas variedades de Ricinus communis, após a crioconservação em nitrogênio líquido a $-196^{\circ} \mathrm{C}$, durante três dias

\begin{tabular}{lccc}
\hline \multirow{2}{*}{ Fatores } & $\begin{array}{c}\text { Germinação } \\
(\%)\end{array}$ & \multicolumn{2}{c}{ Vigor } \\
\cline { 3 - 4 } & & & \\
Variedade & Contagem $(\%)$ & Mat. Seca $(\mathrm{g})$ \\
nordestina & $71,33 \mathrm{a}$ & $71,33 \mathrm{a}$ & $25,51 \mathrm{a}$ \\
pernambucana & $68,00 \mathrm{~b}$ & $68,00 \mathrm{~b}$ & $18,27 \mathrm{~b}$ \\
\hline DMS & 1,17 & 1,17 & 0,61 \\
\hline Teor de Umidade $(\%)$ & & \\
Testemunha & $79,00 \mathrm{a}$ & $79,00 \mathrm{a}$ & $24,55 \mathrm{a}$ \\
4 & $80,00 \mathrm{a}$ & $80,00 \mathrm{a}$ & $25,43 \mathrm{a}$ \\
6 & $80,00 \mathrm{a}$ & $80,00 \mathrm{a}$ & $25,01 \mathrm{a}$ \\
8 & $78,00 \mathrm{a}$ & $78,00 \mathrm{a}$ & $24,67 \mathrm{a}$ \\
10 & $80,00 \mathrm{a}$ & $80,00 \mathrm{a}$ & $25,00 \mathrm{a}$ \\
12 & $21,00 \mathrm{~b}$ & $21,00 \mathrm{~b}$ & $6,70 \mathrm{~b}$ \\
DMS & 3,01 & 3,01 & 1,57 \\
\hline $\begin{array}{l}\text { As médias seguidas pela mesma letra não diferem estatisticamente pelo teste de Tukey, a } 5 \% \text { de } \\
\text { probabilidade }\end{array}$ & \multicolumn{2}{l}{} \\
Testemunha com 6\% b.u.
\end{tabular}

b.u.) devem ser os preferidos para a crioconservação. Esta indicação encontra apoio em trabalhos desenvolvidos com Sesamum indicum por Batista (2000) e por Almeida et al. (2000) em 10 leguminosas crioconservadas com 6 a $7 \%$ de umidade. Em conjunto, esses resultados indicam, para esta faixa de umidade, que a crioconservação pode ser um método adequado para a preservação das sementes das variedades de Ricinus communis estudadas.

Estes resultados condizem com os contidos na Tabela 3, cujo efeito significativo da interação variedade versus teor de umidade, só se deu para a crioconservação da semente de mamona com teor de umidade de $12 \%$ b.u.

Desta Tabela tem-se, para a viabilidade das sementes (germinação e sua primeira contagem) crioarmazenadas, igualdade estatística para $12 \%$ de umidade b.u., frente à testemunha, mas com redução de $73,4 \%$ da sua germinação.

No que se refere à colheita dessas sementes nas regiões produtoras do Nordeste do Brasil, sabe-se que elas são colhidas com umidade em torno de $6 \%$ e, pelo que foi discutido anteriormente, a faixa de umidade de $4-8 \%$ b.u. deve ser a preferida para a crioconservação desse material.

De concreto, tem-se que o conteúdo de umidade das sementes é um dos principais fatores controladores da crioconservação. Sementes de alface foram danificadas quando crioarmazenadas com mais de $18 \%$ de umidade em b.u. (Roos \& Stanwood, 1981). Da mesma forma ocorreu com a crioconservação de sementes de Sesamum indicum com 12\% de umidade (Stanwood, 1987). Segundo o mesmo autor, a uma taxa de congelamento de $200^{\circ} \mathrm{C} \mathrm{min}^{-1}$, observaram-se danos às sementes de Sesamum para um conteúdo de umidade inferior a $6 \%$ b.u., o que leva a se concluir que a taxa de resfriamento pode interagir com o conteúdo de umidade da semente, afetando sua sobrevivência. Este fato põe de sobreaviso a importância de se estabelecer o NMU.

\section{Crioconservação}

A análise de variância (Tabela 4) revelou valores significativos para todas as variáveis, com exceção da variável temperatura, e

Tabela 3. Valores médios* do desdobramento da interação variedade versus teor de umidade para a variável viabilidade das sementes de duas variedades de Ricinus communis crioarmazenadas por três dias

\begin{tabular}{|c|c|c|c|c|c|c|c|}
\hline \multirow{2}{*}{ Variedade } & \multicolumn{6}{|c|}{ Teor de Umidade (\% b.u.) } & \multirow{2}{*}{ Média } \\
\hline & (Test.) & (4) & (6) & $(8)$ & $(10)$ & (12) & \\
\hline \multicolumn{8}{|c|}{ A. Germinação e $1^{\mathrm{a}}$ Contagem (\%) } \\
\hline Nordestina & $80,00 \mathrm{aA}$ & $82,00 \mathrm{aA}$ & $82,00 \mathrm{aA}$ & $80,00 \mathrm{aA}$ & $82,00 \mathrm{aA}$ & $22,00 \mathrm{aB}$ & 71,33 \\
\hline Média & 79,00 & 80,00 & 80,00 & 78,00 & 80,00 & 21,00 & 69,66 \\
\hline \multicolumn{8}{|c|}{ DMS/colunas $=2,87$ (letras minúsculas); DMS/linhas $=4,26$ (letras maiúsculas) } \\
\hline \multicolumn{8}{|c|}{ B. Matéria Seca $(\mathrm{g})$} \\
\hline Pernambucana & $20,50 \mathrm{bA}$ & $21,25 \mathrm{bA}$ & $21,02 \mathrm{bA}$ & $20,60 \mathrm{bA}$ & $20,80 \mathrm{bA}$ & $5,47 \mathrm{bB}$ & 18,27 \\
\hline Média & 24,55 & 25,43 & 25,01 & 24,67 & 25,00 & 3,34 & 21,89 \\
\hline
\end{tabular}

DMS/colunas $=1,50$ (letras minúsculas); DMS/linhas $=$ 2,22 (letras maiúsculas)

"As médias seguidas das mesmas letras maiúsculas nas linhas e minúsculas nas colunas não diferem estatisticamente pelo teste de Tukey em $5 \%$ de probabilidade

Test. $=$ testemunha $(6 \%$ b.u. $)$ 
Tabela 4. Análise de variância da viabilidade das sementes de duas variedades de Ricinus communis, com teor de umidade de $6 \%$ b.u., acondicionadas em canister de PVC e de alumínio e crioconservadas durante 3,30 e $60 \mathrm{~d}$

\begin{tabular}{lcrrr}
\hline Fonte de Variação & $\begin{array}{c}\text { Grau de } \\
\text { Liberdade }\end{array}$ & Germinação & $\begin{array}{c}\text { Primeira } \\
\text { Contagem }\end{array}$ & $\begin{array}{c}\text { Matéria } \\
\text { Seca }\end{array}$ \\
\hline Variedades (V) & 1 & $98,00 * *$ & $98,00 * *$ & $2729,43 * *$ \\
Período (P) & 2 & $8,66 * *$ & $8,66 * *$ & $3,89 *$ \\
Temperatura (T) & 1 & $0,22 \mathrm{~ns}$ & $0,22 \mathrm{~ns}$ & $0,00 \mathrm{~ns}$ \\
Acondicionamento (A) & 1 & $80,22 * *$ & $80,22 * *$ & $43,24 * *$ \\
V x P & 2 & $0,66 \mathrm{~ns}$ & $0,66 \mathrm{~ns}$ & $0,46 \mathrm{~ns}$ \\
V x T & 1 & $5,55 *$ & $5,55 *$ & $15,77 * *$ \\
V x A & 1 & $18,00 * *$ & $18,00 * *$ & $0,02 \mathrm{~ns}$ \\
P x T & 2 & $13,55 * *$ & $13,55 * *$ & $13,26 * *$ \\
P x A & 2 & $0,22 \mathrm{~ns}$ & $0,22 \mathrm{~ns}$ & $2,55 \mathrm{~ns}$ \\
T x A & 1 & $5,55 *$ & $5,55 *$ & $13,47 * *$ \\
V x P x T & 2 & $8,22 * *$ & $8,22 * *$ & $9,22 * *$ \\
V x P x A & 2 & $2,00 \mathrm{~ns}$ & $2,00 \mathrm{~ns}$ & $7,42 * *$ \\
V x T x A & 1 & $18,00 * *$ & $18,00 * *$ & $8,19 * *$ \\
P x T x A & 2 & $1,55 \mathrm{~ns}$ & $1,55 \mathrm{~ns}$ & $0,48 \mathrm{~ns}$ \\
V x P x T x A & 2 & $0,66 \mathrm{~ns}$ & $0,66 \mathrm{~ns}$ & $0,42 \mathrm{~ns}$ \\
Resíduo & 72 & & & \\
\hline Total & 95 & & &
\end{tabular}

Total 95

* F significativo ao nível de $5 \%$ de probabilidade

ns F não significativo

que as interações variedade versus período e período versus acondicionamento de segunda ordem, não foram significativas estatisticamente.

Nos ensaios de viabilidade das sementes crioarmazenadas por 3, 30 e 60 dias, obtidos pelo teste de germinação e vigor (primeira contagem da germinação e matéria seca) para as variáveis variedade, período, temperatura e acondicionamento (Tabela 5) e sua interação de segunda ordem (Tabelas de 6 a 9) tem-se comportamento similar para todos os fatores da Tabela 5 , na qual se verifica que a variedade nordestina foi superior à pernambucana e que, em comparação com os valores absolutos antes da crioconservação, estes foram superiores em 3,0 e 1,5 pontos percentuais de viabilidade e 2,92 e 0,33 de matéria seca, respectivamente, para as variedades estudadas, na ordem apresentada. Esses resultados são devidos, provavelmente, às mudanças de temperatura e à expansão do nitrogênio líquido durante o reaquecimento, que originaram quebra de dormência nessas sementes. A diferença que se observa, entre variedades pode ser devida à sua composição química e/ou à sensibilidade das sementes aos danos físicos, conforme observado por Almeida et al. (2000) ao afirmarem que as sementes com maior conteúdo de óleo, parecem ser mais susceptíveis à crioconservação se bem que, segundo Iriondo et al. (1992) não está claro a existência de uma correlação entre a sensibilidade das sementes com a crioconservação e seu conteúdo de óleo; no entanto, Stanwood (1980) destaca que o efeito da crioconservação pode variar entre cultivares da mesma espécie, destacando sua atuação em algumas sementes de leguminosas (Stanwood, 1985).

Para o fator período de crioconservação, verifica-se maior germinação aos 30 dias, retornando esta ao nível inicial, aos 60 dias da crioconservação. Sobre o tema, Batista (2000) obteve, para duas variedades de Sesamum indicum, maior porcentagem
Tabela 5. Valores médios* da crioconservação sobre a viabilidade das sementes de duas variedades de Ricinus communis, com teor de umidade de $6 \%$ b.u., acondicionadas em canister de PVC e de alumínio, durante 3,30 e 60 d

\begin{tabular}{|c|c|c|c|}
\hline Fatores & $\begin{array}{c}\text { Germinação } \\
(\%)\end{array}$ & $\begin{array}{c}1^{a} \text { Cont. Ger. } \\
(\%)\end{array}$ & $\begin{array}{l}\text { Mat. Seca } \\
(\mathrm{g})\end{array}$ \\
\hline \multicolumn{4}{|l|}{ A. Variedade } \\
\hline Nordestina & $81,00 \mathrm{a}$ & $81,00 \mathrm{a}$ & $29,32 \mathrm{a}$ \\
\hline Pernambucana & $77,50 \mathrm{~b}$ & $77,50 \mathrm{~b}$ & $20,63 \mathrm{~b}$ \\
\hline DMS & 0,70 & 0,70 & 0,33 \\
\hline \multicolumn{4}{|l|}{ B. Período } \\
\hline 3 dias & $78,50 \mathrm{~b}$ & $78,50 \mathrm{~b}$ & $24,70 \mathrm{~b}$ \\
\hline 30 dias & $80,25 \mathrm{a}$ & $80,25 \mathrm{a}$ & $25,27 \mathrm{a}$ \\
\hline 60 dias & $79,00 \mathrm{~b}$ & $79,00 \mathrm{~b}$ & $24,94 \mathrm{a} \mathrm{b}$ \\
\hline DMS & 1,03 & 1,03 & 0,48 \\
\hline \multicolumn{4}{|l|}{ C. Temperatura } \\
\hline Vapor de NL & $79,16 \mathrm{a}$ & 79,16 a & $24,98 \mathrm{a}$ \\
\hline Imersão em NL & $79,33 \mathrm{a}$ & $79,33 \mathrm{a}$ & $24,97 \mathrm{a}$ \\
\hline DMS & 0,70 & 0,70 & 0,33 \\
\hline \multicolumn{4}{|l|}{ D. Acondicionamento } \\
\hline Canister de PVC & $77,66 \mathrm{~b}$ & $77,66 \mathrm{~b}$ & $24,42 \mathrm{~b}$ \\
\hline Canister de Alumínio & $80,83 \mathrm{a}$ & $80,83 \mathrm{a}$ & $25,52 \mathrm{a}$ \\
\hline DMS & 0,70 & 0,70 & 0,33 \\
\hline
\end{tabular}

Tabela 6. Valores médios* do desdobramento da interação variedade versus temperatura de crioconservação para a variável viabilidade das sementes com teor de umidade de $6 \%$ b.u., submetida a crioconservação em dois tipos de acondicionamento por três períodos

\begin{tabular}{|c|c|c|c|}
\hline \multirow{2}{*}{ Variedade } & \multicolumn{2}{|c|}{ Temperatura de Crioconservação $\left({ }^{\circ} \mathrm{C}\right)$} & \multirow{2}{*}{ Média } \\
\hline & $(-176)$ & $(-196)$ & \\
\hline \multicolumn{4}{|c|}{ A. Germinação e $1^{\text {a }}$ Contagem $(\%)$} \\
\hline Nordestina & $81,33 \mathrm{aA}$ & $80,66 \mathrm{aA}$ & 80,99 \\
\hline Pernambucana & $77,00 \mathrm{bB}$ & $78,00 \mathrm{bA}$ & 77,50 \\
\hline Média & 79,16 & 79,33 & 79,24 \\
\hline \multicolumn{4}{|c|}{ DMS/colunas $=0,99$ (letras minúsculas) } \\
\hline
\end{tabular}

\begin{tabular}{llll}
\hline B. Matéria seca $(\mathrm{g})$ & & & \\
Nordestina & $29,65 \mathrm{aA}$ & $28,98 \mathrm{aB}$ & 29,31 \\
Pernambucana & $20,30 \mathrm{bB}$ & $20,95 \mathrm{bA}$ & 20,62 \\
Média & 24,97 & 24,96 & 24,96 \\
\hline
\end{tabular}

DMS/colunas $=0,46$ (letras minúsculas)

DMS/linhas $=0,46$ (letras maiúsculas)

* As médias seguidas das mesmas letras maiúsculas nas linhas e minúsculas nas colunas não diferem estatisticamente pelo teste de Tukey, em $5 \%$ de probabilidade

de germinação depois de 60 dias das sementes imersas em nitrogênio líquido, frente à germinação calculada aos 5 e 30 dias de crioconservação. Almeida et al. (2000) também encontraram, para algumas sementes de leguminosas, depois de sua imersão em nitrogênio líquido, respostas heterogêneas, porém em 6 dessas amostras a viabilidade foi menor. Para os autores, nem o conteúdo de umidade nem o tamanho das sementes nem, ainda, a velocidade de resfriamento ou de reaquecimento, parecem justificar as respostas observadas para a imersão em nitrogênio líquido das sementes avaliadas. 
Tabela 7. Valores médios* do desdobramento da interação variedade versus acondicionamento das sementes para a variável viabilidade das sementes com teor de umidade de $6 \%$ b.u., submetidas a crioconservação em dois tipos de acondicionamento por três períodos

\begin{tabular}{llll}
\hline \multirow{2}{*}{ Variedade } & \multicolumn{2}{c}{$\begin{array}{c}\text { Acondicionamento das } \\
\text { Sementes em Canister }\end{array}$} & \multirow{2}{*}{ Média } \\
\cline { 2 - 3 } & \multicolumn{1}{c}{$($ PVC) } & (alumínio) & \\
\hline A. Germinação e $1^{\text {a }}$ Contagem (\%) & & \\
Nordestina & $78,66 \mathrm{aB}$ & $83,33 \mathrm{aA}$ & 81,00 \\
Pernambucana & $76,66 \mathrm{bB}$ & $78,33 \mathrm{bA}$ & 77,49 \\
Média & 77,66 & 80,83 & 79,24 \\
\hline
\end{tabular}

DMS/colunas $=0,99$ (letras minúsculas)

DMS/linhas $=0,99$ (letras maiúsculas)

\begin{tabular}{llll}
\hline B. Matéria Seca $(\mathrm{g})$ & & & \\
Nordestina & $28,78 \mathrm{aB}$ & $29,85 \mathrm{aA}$ & 29,31 \\
Pernambucana & $20,07 \mathrm{bB}$ & $21,18 \mathrm{bA}$ & 20,62 \\
Média & 24,42 & 25,51 & 24,96 \\
\hline
\end{tabular}

DMS/colunas $=0,46$ (letras minúsculas)

DMS/linhas $=0,46$ (letras maiúsculas)

* As médias seguidas das mesmas letras maiúsculas nas linhas e minúsculas nas colunas não diferem estatisticamente pelo teste de Tukey, em $5 \%$ de probabilidade

Tabela 8. Valores médios ${ }^{*}$ do desdobramento da interação período versus temperatura de crioconservação para a variável viabilidade das sementes com teor de umidade de $6 \%$ b.u., submetidas a crioconservação em dois tipos de acondicionamento por três períodos

\begin{tabular}{lccc}
\hline $\begin{array}{c}\text { Período de } \\
\text { Crioconservação } \\
\text { (dias) }\end{array}$ & \multicolumn{2}{c}{$\begin{array}{c}\text { Temperatura de } \\
\text { Crioconservação }\left({ }^{\circ} \mathrm{C}\right)\end{array}$} & Média \\
\cline { 1 - 3 } & $(-176)$ & $(-196)$ & \\
\hline A. Germinação e $1^{\mathrm{a}}$ Contagem (\%) & & \\
(3) & $79,50 \mathrm{aA}$ & $77,50 \mathrm{cB}$ & 78,50 \\
$(30)$ & $79,00 \mathrm{aB}$ & $81,50 \mathrm{aA}$ & 80,25 \\
$(60)$ & $79,00 \mathrm{aA}$ & $79,00 \mathrm{bA}$ & 79,00 \\
Média & 79,17 & 79,33 & 79,25 \\
\hline
\end{tabular}

DMS/colunas $=1,46$ (letras minúsculas)

DMS/linhas $=1,22$ (letras maiúsculas)

\begin{tabular}{llll}
\hline B. Matéria Seca (g) & & & \\
$(3)$ & $25,19 \mathrm{aA}$ & $24,22 \mathrm{bB}$ & 24,70 \\
$(30)$ & $24,71 \mathrm{aB}$ & $25,83 \mathrm{aA}$ & 25,27 \\
$(60)$ & $25,02 \mathrm{aA}$ & $24,86 \mathrm{bA}$ & 24,94 \\
Média & 24,97 & 24,97 & 24,97 \\
\hline
\end{tabular}

DMS/colunas $=0,69$ (letras minúsculas)

DMS/linhas $=0,57$ (letras maiúsculas)

* As médias seguidas das mesmas letras maiúsculas nas linhas e minúsculas nas colunas não diferem estatisticamente pelo teste de Tukey, em $5 \%$ de probabilidade

No presente estudo, o fato se deveu, provavelmente, à adaptação das sementes à crioconservação, o que vem a concordar com Stanwood \& Roos (1979) que obtiveram 91, 95 e $93 \%$ de germinação para Capsicum frutescens depois de 7, 30 e 180 dias, respectivamente, após a crioconservação.

A temperatura não exerce influência sobre a viabilidade e o acúmulo de matéria seca das duas variedades de Ricinus communis estudadas. Este comportamento se apresenta como vantagem deste material à crioconservação, pois o nitrogênio líquido é volátil e pode alterar a temperatura interna dos botijões criobiológicos; já para o fator acondicionamento, o canister de PVC apresentou-se inferior estatisticamente ao de alumínio
Tabela 9. Valores médios* do desdobramento da interação temperatura versus acondicionamento das sementes para a variável viabilidade das sementes com teor de umidade de $6 \%$ b.u., submetidas a crioconservação em dois tipos de acondicionamento por três períodos

\begin{tabular}{|c|c|c|c|}
\hline \multirow{2}{*}{$\begin{array}{l}\text { Temperatura de } \\
\text { Crioconservação } \\
\left({ }^{\circ} \mathrm{C}\right)\end{array}$} & \multicolumn{2}{|c|}{ Acondicionamento das } & \multirow[t]{2}{*}{ Média } \\
\hline & (PVC) & (alumínio) & \\
\hline \multicolumn{4}{|c|}{ A. Germinação e $1^{\text {a }}$ Contagem (\%) } \\
\hline$(-176)$ & $78,00 \mathrm{aB}$ & $80,33 \mathrm{aA}$ & 79,16 \\
\hline$(-196)$ & $76,33 \mathrm{bB}$ & $81,33 \mathrm{bA}$ & 79,33 \\
\hline Média & 77,66 & 80,83 & 79,24 \\
\hline \multicolumn{4}{|c|}{ DMS/colunas = 0,99 (letras minúsculas) } \\
\hline \multicolumn{4}{|c|}{ B. Matéria Seca $(\mathrm{g})$} \\
\hline$(-176)$ & $24,73 \mathrm{aB}$ & $25,22 \mathrm{aA}$ & 24,97 \\
\hline$(-196)$ & $24,12 \mathrm{bB}$ & $25,82 \mathrm{bA}$ & 24,97 \\
\hline Média & 24,42 & 25,52 & 24,97 \\
\hline
\end{tabular}

DMS/colunas $=0,46$ (letras minúsculas)

DMS/linhas $=0,46$ (letras maiúsculas)

* As médias seguidas das mesmas letras maiúsculas nas linhas e minúsculas nas colunas não diferem estatisticamente pelo teste de Tukey, em $5 \%$ de probabilidade

devido, talvez, à velocidade de congelamento admitida por esses materiais, sendo o canister de PVC dotado de uma condutividade térmica menor que a de alumínio, o que deve ter favorecido a velocidade de emergência (Tabela 5).

Os resultados da germinação e do vigor, expressos pela primeira contagem da germinação e pela matéria seca, deixam claro os efeitos imediatos da interação variedade versus temperatura de crioconservação (Tabela 6) indicando que a variedade pernambucana se comportou de forma inferior quando submetida ao vapor do nitrogênio líquido $\left(-176^{\circ} \mathrm{C}\right) \mathrm{e}$ que a viabilidade da variedade nordestina teve o mesmo comporta-mento, tanto na crioconservação a $-176^{\circ} \mathrm{C}$, quanto a $-196^{\circ} \mathrm{C}$, porém o comportamento da matéria seca foi variável, tendo sido maior para a variedade nordestina crioconservada no vapor do nitrogênio líquido $\left(-176^{\circ} \mathrm{C}\right)$ e a pernambucana imersa diretamente no nitrogênio líquido, resultados que, em parte, diferem dos obtidos por Diniz (1999) que trabalhou com Zea mays e constatou melhor viabilidade para a crioconservação das sementes submetidas ao vapor do nitrogênio líquido $\left(-176^{\circ} \mathrm{C}\right)$.

De acordo com a Tabela 7, as médias estatisticamente significativas para a interação variedades versus acondicionamento das sementes, confirmam a discussão apresentada anteriormente sobre a superioridade da variedade nordestina em relação à pernambucana, com respeito à sua viabilidade expressa pela germinação e vigor (primeira contagem e a matéria seca); entretanto tem-se, mediante esta tabela, que as sementes crioconservadas em canister de alumínio mantiveram maior média de viabilidade que as crioconservadas em canister de $\mathrm{PVC}$, indicando efeito do material usado para acondicionar as sementes sobre o comportamento da germinação e da matéria seca das variedades de mamona estudadas.

Os dados da interação período versus temperatura de crioconservação, apresentados na Tabela 8 , indicam que não 
houve efeito estatístico do tempo (período de crioconservação) sobre a viabilidade das sementes no vapor do nitrogênio líquido $\left(-176^{\circ} \mathrm{C}\right)$ e que a imersão das sementes no nitrogênio líquido $\left(-196^{\circ} \mathrm{C}\right)$ apresentou comportamento de viabilidade diferente, tendo a viabilidade, aos 30 dias, sido superior à de 60 dias, para a germinação e sua primeira contagem; no entanto, para a matéria seca tem-se igualdade estatística do seu acúmulo para esses dois períodos (3 e 60 dias). Com relação às temperaturas da crioconservação $\left(-176 \mathrm{e}-196^{\circ} \mathrm{C}\right)$ as variedades tiveram o mesmo comportamento do ponto de vista da estatística, com diferença de que conferem superioridade para as sementes crioconservadas a $-196{ }^{\circ} \mathrm{C}$ aos 30 dias frente às submetidas a $-176^{\circ} \mathrm{C}$ (vapor do nitrogênio); destaca-se que o comportamento das sementes crioconservadas no vapor do nitrogênio e diretamente no nitrogênio líquido, é diferente ao longo dos três períodos, mas com igualdade estátistica no terceiro período (60 dias).

Mediante a exposição dos dados da interação temperatura versus acondicionamento (Tabela 9) verifica-se igualdade estatística para as temperaturas estudadas, ao se analisar a germinação das sementes e sua primeira contagem, quando acondicionadas em canister de PVC. Com a matéria seca, o comportamento foi diferente e as sementes acondicionadas em canister de PVC se comportaram com superioridade estatística quando crioconservadas no vapor do nitrogênio líquido $\left(-176^{\circ} \mathrm{C}\right)$ frente às imersas diretamente no nitrogênio líquido $\left(-196^{\circ} \mathrm{C}\right)$. Para o acondicionamento em canister de alumínio, a germinação, sua primeira contagem e a matéria seca, tiveram o mesmo comportamento do ponto de vista estatístico, com respeito às temperaturas estudadas, tendo a temperatura de $-196{ }^{\circ} \mathrm{C}$ favorecido a viabilidade das sementes verificadas por esses fatores.

Observa-se, ainda, na referida tabela, para os materiais utilizados no acondicionamento das sementes, superioridade do canister de alumínio em relação ao de PVC.

\section{CONCLUSÕES}

1. Os melhores resultados de qualidade fisiológica das variedades de Ricinus communis estudadas (nordestina e pernambucana) foram obtidos aos 30 dias de crioconservação, tanto no vapor $\left(-176^{\circ} \mathrm{C}\right)$ como na imersão $\left(-196^{\circ} \mathrm{C}\right)$ em nitrogênio líquido.

2. O canister de alumínio utilizado para acondicionar as sementes, mostrou-se superior ao canister de PVC, quando imerso em nitrogênio líquído.

3. As sementes das variedades de Ricinus communis estudadas, podem ser crioarmazenadas com a umidade de colheita, que está em torno de $6 \%$ b.u. nas regiões produtoras do Nordeste do Brasil.

\section{LITERATURA CITADA}

Almeida, F. de A.C.; Matos, V.R.; Castro, J.R. de; Dutra, A.S. Avaliação da qualidade e conservação de sementes a nível de produtor. In: Almeida, F. de A.C.; Hara, T.; Cavalcanti Mata, M.E.R.M. (ed.). Armazenamento de grãos e sementes nas propriedades rurais. Campina Grande: UFPB/SBEA, 1997.201p.
Almeida, F. de A.C.; Pita Villamil, J.M.; Gouveia, J.P.G. de. Efeito de la crioconservacion sobre la germinacion de semillas de leguminosas. Revista Brasileira de Produtos Agroindustriais, Campina Grande, v.2, n.1, p.67-71, 2000.

Azevedo, D.M.P. de.; Lima, E.F.; Batista, F.A.S.; Beltrão, N.E. de M.; Soares, J.J.; Vieira, R.M.; Moreira, J. de A.N. Recomendações técnicas para o cultivo da mamoneira (Ricinus communis L.) no Nordeste do Brasil. Campina Grande: Embrapa-CNPA, 1997. 52p. Circular Técnica, 25

Batista, R.C. Cultivo in vitro e criopreservação de sementes de gergelim (Sesamum indicum L.). Campina Grande: DEAg/ CCT/UFPB, 2000, 83p. Dissertação Mestrado

Brasil. Ministério da Agricultura. Regras para análise de sementes. Brasília: SNDA/DNDV/CLAV, 1992.365p.

Cunha, R. da. Cultura de tecidos na conservação de germoplasma vegetal. In: Puignau, J.P. (ed.) Conservación de germoplasma vegetal. Monte Video: IICA, 1996. p. 129138. IICA-PROCISUR, Dialogo, 45.

Diniz, P.S.C. Qualidade fisiológica das sementes de milho (Zea mays L.) submetidas a diferentes técnicas de crioconservação. Campina Grande: DEAg/CCT/UFPB. 1999, 80p. Dissertação Mestrado

Engelmann, F. Importance of cryopreservation for the conservation of plant genetic resources. In: Engelmann, F. (ed.). Cryopreservation of tropical plant germoplasm.. Italia: International Plant Genetic Resouces Institute, 2000, p.8-20.

González-Benito, M.E.; Carvalho, J.M.F.C.; Pérez, C. Effect of desiccation and cryopreservation on the germination of embryonic axes and seeds of cotton. Pesquisa Agropecuária Brasileira, Brasília, v.33, n.1, p.17-20, 1998.

Henshaw, G.G.; Stamp, J.A.; Westcott, J.J. Tissue cultures and germplsm storage. In: Sala, F.; Parisi, B.; Cella, R.; Ciferri, O. (eds.), Plant Cell Cultures: results and perspectives. Amsterdan: Elsevier. 1980. p.277-282.

Iriondo, J.M.; Perez, C.; Perez-Garcia, F. Effect of seed storage in liquid nitrogen on germination of several crop and wild species. Seed Science and Technology, Zurich Suiça, v.20, n.1, p.165-171, 1992.

IBGE - Instituto Brasileiro de Geografia e Estatística. Levantamento sistemático da produção agrícola. Rio de Janeiro. 1975. 19p.

IBGE - Instituto Brasileiro de Geografia e Estatística. Levantamento sistemático da produção agrícola. Rio de Janeiro. 2001.74p.

Kartha, K.K. Meristem culture and germplasm preservation. In: Kartha, K.K. (ed.). Cryopresevation of plant cells and organs. Boca Roton: CRS Press. 1985, p.115-134.

Roos, E.E.; Stanwood, P.C. Effects of low temperature, cooling rate and moisture content on seed germination of lettuce. Journal of the American Society for Horticultural Science, Mount Vernon, n.106, p.30-34, 1981.

Silva, F.de A.S.e. The ASSISTAT Software: statistical assistance. In: International Conference on Computers in Agriculture, 6,Cancun, 1996. Proceedings... Cancun: American Society of Agricultural Engineers, 1996. p.294-298. 
Stanwood, P.C. Tolerance of crops seeds to cooling and storage in liquid nitrogen $\left(-196^{\circ} \mathrm{C}\right)$. Journal of Seed Technology, USA. v.5, n.1, p.26-31, 1980.

Stanwood, P.C.; Bass, L.N. Seed germplasm preservation using liquid nitrogen. Seed Science and Technology, Zurich-Suiça, n.9, p.423-437, 1981.

Stanwood, P.C.; Roos, E.E. Seed storage of several horticultural species in liquid nitrogen $\left(-196^{\circ} \mathrm{C}\right)$. HortScience, v.14 n.5, p.628-630, 1979.
Stanwood, P.C. Cryopreservation of seed germplasm for genetic conservation In: Kartha, K.K. (ed.). Cryopreservation of plant cells and organs. Boca Rotan: CRC Press, 1985. p.199-225.

Stanwood, P.C. Survival of sesame seeds at the temperature $\left(-196^{\circ} \mathrm{C}\right)$ of liquid nitrogen. Crop Scince, Madison - WI, v.27, p.327-331, 1987.

Vertucci, C.W. Effects of cooling rate on seeds exposed to liquid nitrogen temperatures. Plant Physiology, Bethesda MD, v.90, p.1478-1485, 1989. 